\title{
ASSESSMENT OF EFFICACY AND SAFETY OF ORAL FOSFOMYCIN SINGLE DOSE IN UNCOMPLICATED URINARY TRACT INFECTION AT A TERTIARY CARE HOSPITAL IN SOUTH INDIA
}

\author{
SASHIDHAR REDDY B*, MANOJ KUMAR YADAV M, MANISHA S, SANGI REDDY SAI SREE, \\ SUNKARA HEMA KAMALA
}

Department of General Medicine, RVM Institute of Medical Sciences and Charitable Trust Hospital, Siddipet, Telangana, India. Email: shashidhar.bommineni@gmail.com

Received: 14 September 2021, Revised and Accepted: 25 December 2021

\begin{abstract}
Objectives: Urinary tract infection (UTI) affects 150 million people worldwide each year. The rise in the UTIs is attributed to multidrug-resistant pathogens for which there are minimal treatment options available. This has facilitated the reemergence of certain old antimicrobials such as fosfomycin trometamol (FT). It seems an alternative, but the evidence towards its therapeutic efficiency is scanty. The objective of the study is to evaluate the safety and efficacy of single dose of FT in treating uncomplicated UTI and the resultant variations in the intensity of symptoms after the treatment.
\end{abstract}

Methods: The study is a prospective, observational, and open-label study in the outpatient unit of the Department of General Medicine, RVM institute of Medical Sciences, for 6 months. The study comprises 50 patients among the age group of 18-70 years. Urinary Tract Infection Symptom Assessment questionnaire was used for the evaluation of symptoms pre and post treatment. After the diagnosis of uncomplicated UTI, patients were treated with single-dose of FT.

Results: The study comprises 22 males and 28 females. After the treatment, there was a drastic improvement in the condition of patients. The severity level reduced and the quality of life improved post treatment and the results were statistically significant. Among 50 patients treated with the drug, 11 patients reported the side effect of diarrhea.

Conclusion: Single dose oral Fosfomycin (3 g) regimen is effective in managing uncomplicated UTI with minimal side effects.

Keywords: Urinary tract infection, Fosfomycin trometamol, Effectiveness, Adverse effects.

(C) 2022 The Authors. Published by Innovare Academic Sciences Pvt Ltd. This is an open access article under the CC BY license (http://creativecommons.org/ licenses/by/4.0/) DOI: http://dx.doi.org/10.22159/ajpcr.2022v15i2.43133. Journal homepage: https://innovareacademics.in/journals/index.php/ajpcr

\section{INTRODUCTION}

Urinary tract infection (UTI) is the most common bacterial infection seen worldwide and affects approximately 150 million people every year [1]. The infection is more common among females [2,3]. The increased use of antibiotics has led to emergence of resistance which, in turn, are leading to recurrent infections. Recurrent UTI have a high impact on quality of life of patients' and hence optimum use of antibiotics should be of high priority [4]

Evolution of increased bacterial resistance and accessibility of restricted options of antimicrobials have facilitated reemergence of certain old antibiotic agents such as fosfomycin trometamol (FT) [1,5]. Fosfomycin is an oral, uroselective, broad spectrum antibiotic with high efficacy against Gram-positive and Gram-negative pathogens [1]. A single-dose FT can serve a relevant role in uncomplicated UTI treatment specifically in patients with impaired drug compliance. Due to less evidence on the clinical effectiveness of FT, the present study focuses on assessing safety-efficacy of it in uncomplicated UTI's.

The objective of the study is to assess the safety and efficacy of single dose FT after treatment of uncomplicated UTI. The secondary objective is to identify the adverse effects caused by FT.

\section{METHODS}

\section{Study design}

It is an observational, prospective, and open-label study conducted at outpatient unit of Department of General Medicine, RVM Institute of Medical Sciences and Research Centre, for a period of 6 months after the approval of Ethical committee. All the patients among age group 18-70 years diagnosed with uncomplicated UTI were assigned to receive treatment.

Subjects who are willing to participate and who were having the symptoms of UTI, that is, frequency, urgency, burning urine, not able to empty urine completely, lower abdominal pain, and low back ache were included in the study. Complete blood counts and complete urine examination (CUE) were done and findings suggestive of UTI (CUE showing high pus cells and albuminuria) were included in the study.

Urinary tract infection symptom assessment (UTISA) questionnaire was prepared to know the severity of the symptoms and its impact on the quality of life [4]. The UTISA questionnaire is a pro forma which enquires about the severity and bothersomeness of 7 key UTI symptoms. The response to the treatment was assessed by comparing the UTISA scores before and after treatment.

FT is a phosphonic acid derivative act by inhibiting biosynthesis of peptidoglycans required for bacterial cell wall synthesis [6]. Treatment was given with single-dose $3 \mathrm{~g}$ of FT and follow-up was done after 3-5 days of drug administration to assess the improvement in patient's condition.

Subjects who did not give consent, those with complicated UTI, pregnancy and lactation, renal failure, and diabetics were excluded from the study. 


\section{Statistical analysis}

Comparisons were done using Pearson Chi-square analysis of categorical data between groups. Mean and standard deviation were statistically done by Paired two-sample t-test. Comparison between study group, lab parameters, clinical features score was made using Wilcoxon Signed

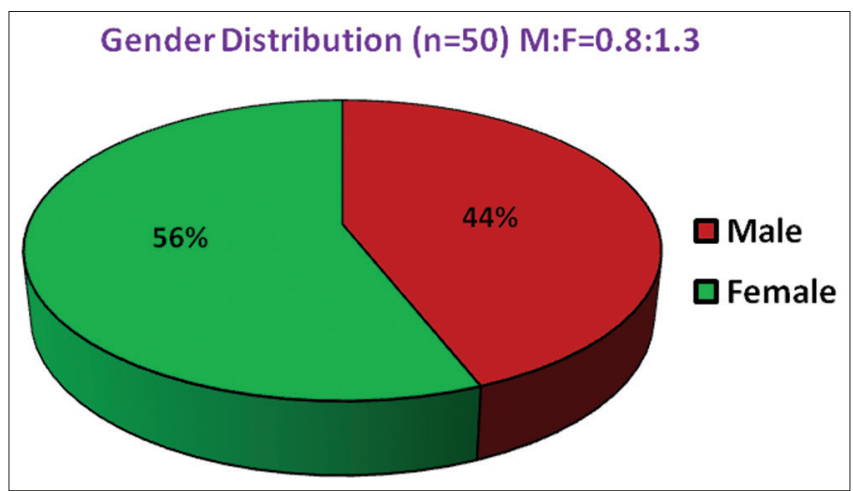

Fig. 1: Gender distribution

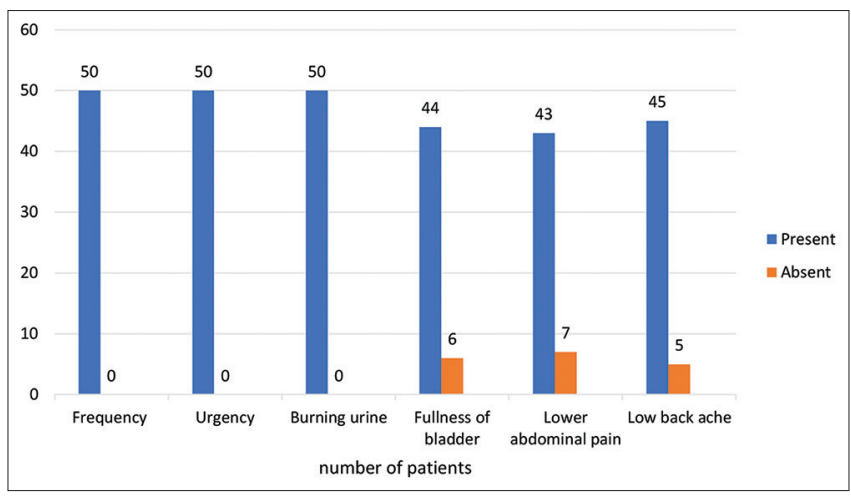

Fig. 2: Symptoms at visit

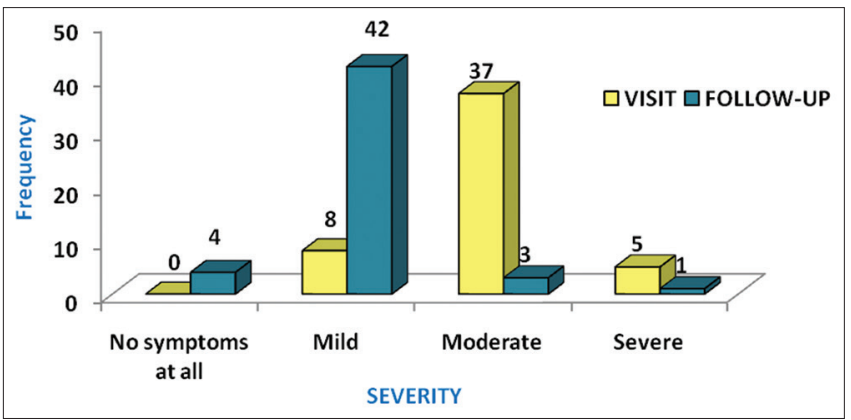

Fig. 3: Overall severity of symptoms
Ranks Test, and correlation of coefficient was calculated. All statistical analyses were processed using SPSS statistical software version 22 and $\mathrm{p}<0.05$ was considered significant.

\section{RESULTS}

A total of 50 samples were obtained during the study period. Of which 22 were males and 28 were females (Fig. 1).

All the subjects who visited out patient department had frequency, urgency, and burning micturition and 88\% patients complained of difficulty in passing urine at visit. Around $86 \%$ had lower abdominal pain and $90 \%$ had low back ache attributable to UTI during the visit (Fig. 2).

All the symptoms such as frequency, urgency, burning, complete emptying, lower abdominal pain, and low back ache were evaluated for the severity during visit and follow-up period (Table 1 ). The symptoms were reduced after the treatment and the results were statistically significant.

Overall rating of the severity of symptoms showed a significant reduction (Table 2 and Fig. 3). The patients who showed moderate and severe symptoms during visit were $42(84 \%)$ and this has drastically reduced to $4(8 \%)$ during follow-up $(\mathrm{p}=0.00)$.

The study compares the laboratory parameters and it depicts a positive correlation of white blood cell (WBC) and pus cells before and after treatment (Table 3). The values of neutrophils, pus cells, and WBC during visit and follow-up are shown in Figs. 4 and 5, respectively.

\section{Albuminuria at visit and follow-up}

Fall in the percentage of albuminuria is seen after treatment (Fig. 6).

The severity of symptoms was compared with the impact on quality of life (Table 4).

All the domains showed progress in the clinical features after the treatment. Effect of symptoms on daily life grading drastically improved post-treatment. Values are statistically significant (Figs. 7 and 8).

Side effects of the drug were noted during the follow-up period. Of 50 patients studied, 11 of them reported diarrhea (Fig. 9).

\section{DISCUSSION}

Uncomplicated UTI is an infection occurring in a structurally and functionally normal urinary tract. In general, 7-10 days of antibiotic are routinely given for such patients [6].

In the current study, majority of the patients were females (56\%) which is in accordance with other studies [4,5]

The UTISA questionnaire is employed to assess symptoms caused due to uncomplicated UTI. It comprises a pre-treatment and post-treatment questionnaires. It served as a valuable tool to know the magnitude of

Table 1: Symptoms severity

\begin{tabular}{|c|c|c|c|}
\hline \multirow[t]{2}{*}{ Symptoms severity } & \multicolumn{2}{|c|}{ Study group } & \multirow[t]{2}{*}{ (z-value and $P$ value) } \\
\hline & Visit & Follow up & \\
\hline Frequency of urination (going to toilet very often) & $2.38 \pm 0.67$ & $0.68 \pm 0.68$ & $\left(6.121,0.0000^{*}\right)$ \\
\hline Pain or burning when passing urine & $1.84 \pm 0.74$ & $0.56 \pm 0.64$ & $\left(5.801,0.0000^{*}\right)$ \\
\hline $\begin{array}{l}\text { Not being able to empty bladder completely/passing only } \\
\text { small amts. of urine }\end{array}$ & $1.52 \pm 0.84$ & $0.26 \pm 0.44$ & $\left(5.646,0.0000^{*}\right)$ \\
\hline $\begin{array}{l}\text { Pain or uncomfortable pressure in lower abdomen/pelvic } \\
\text { area caused by your UTI }\end{array}$ & $1.52 \pm 0.91$ & $0.22 \pm 0.42$ & $\left(5.562,0.0000^{*}\right)$ \\
\hline Low back pain caused by your UTI & $1.54 \pm 0.91$ & $0.26 \pm 0.49$ & $\left(5.559,0.0000^{*}\right)$ \\
\hline
\end{tabular}

Values expressed in S.D \pm mean *Values are statistically significant by Wilcoxon Signed Ranks Test; $P<0.05$. UTI: Urinary tract infection 
Table 2: Overall rating of severity of UTI symptoms

\begin{tabular}{llllll}
\hline \multirow{2}{*}{ Group } & \multicolumn{2}{l}{ Overall rating of severity of your UTI symptoms } & \multicolumn{2}{c}{ Mean \pm S.D } & \\
\cline { 2 - 5 } & No symptoms at all & Mild & Moderate & Severe & \\
\hline Visit & 0 & 8 & 37 & 5 & $1.94 \pm 0.51$ \\
Follow-up & 4 & 42 & 3 & 1 & $1.02 \pm 0.47$ \\
\hline *Value and P value) & $\left(6.099,0.0000^{*}\right)$ \\
\hline
\end{tabular}

*Values are statistically significant by Wilcoxon Signed Rank test; $\mathrm{P}<0.05$. UTI: Urinary tract infection

Table 3: Lab parameters WBC, neutrophils, and pus cells at visit and follow-up

\begin{tabular}{llll}
\hline Lab parameter & Study group & & (t-value and P value) \\
\cline { 2 - 3 } & Visit & Follow up & \\
\hline WBC & $9038 \pm 2086.09$ & $8234 \pm 1760.17$ & $\left(5.03,0.0000^{*}\right)$ \\
Neutrophils & $67.52 \pm 9.14$ & $62.20 \pm 7.68$ & $\left(6.90,0.0000^{*}\right)$ \\
Pus cells & $7.90 \pm 1.30$ & $3.20 \pm 0.95$ & $\left(29.91,0.0000^{*}\right)$ \\
\hline
\end{tabular}

Values are expressed as mean \pm S.D. *Values are statistically significant by paired two sample t-test; $\mathrm{P}<0.05$. WBC: White blood cell

Table 4: Effect of symptoms on daily life

\begin{tabular}{llr}
\hline Impact on life & Study group & (z-value and P value) \\
\cline { 2 - 3 } & Visit & Follow up \\
\hline $\begin{array}{l}\text { Frequency of urination (going to toilet very often) } \\
\text { Urgency of urination (a strong and uncontrollable urge to }\end{array}$ & $2.36 \pm 0.78$ & $0.46 \pm 0.73$ \\
pass urine) & $2.04 \pm 0.78$ & $0.24 \pm 0.52$ \\
When passing urine Pain/burning sensation & $1.88 \pm 0.63$ & $0.26 \pm 0.53$ \\
Not being able to empty bladder completely/passing only & $1.70 \pm 0.86$ & $0.14 \pm 0.45$ \\
$\begin{array}{l}\text { small amts. of urine } \\
\text { Pain or uncomfortable pressure in lower abdomen/pelvic } \\
\text { area caused by your UTI }\end{array}$ & $1.68 \pm 0.91$ & $\left(6.17,0.0000^{*}\right)$ \\
Low back pain caused by UTI & & $\left(5.90,0.0000^{*}\right)$ \\
\hline
\end{tabular}

Values are expressed in mean \pm S.D. *Values are statistically significant by Wilcoxon Signed Ranks Test; P<0.05. UTI: Urinary tract infection

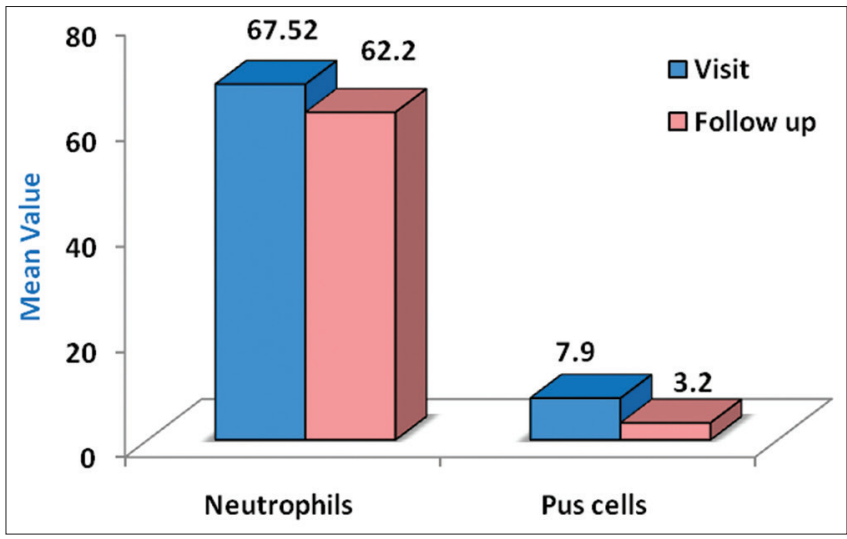

Fig. 4: Neutrophils and pus cells during visit and follow-up

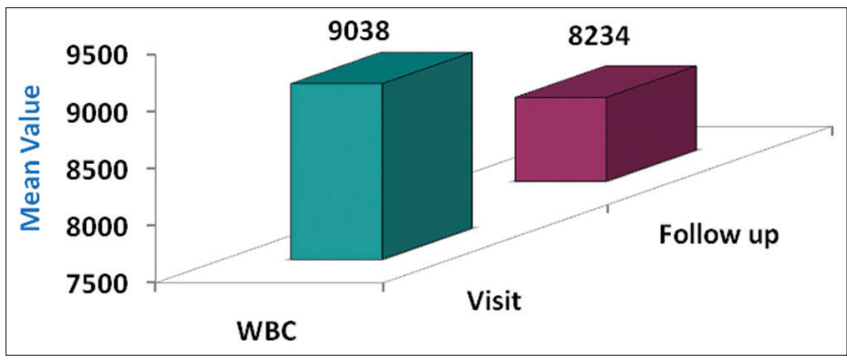

Fig. 5: White blood cell CIUNTS during visit and follow-up

clinical manifestations and their effect on the quality of daily life. This questionnaire was used even in other studies to know the severity of symptoms [7].

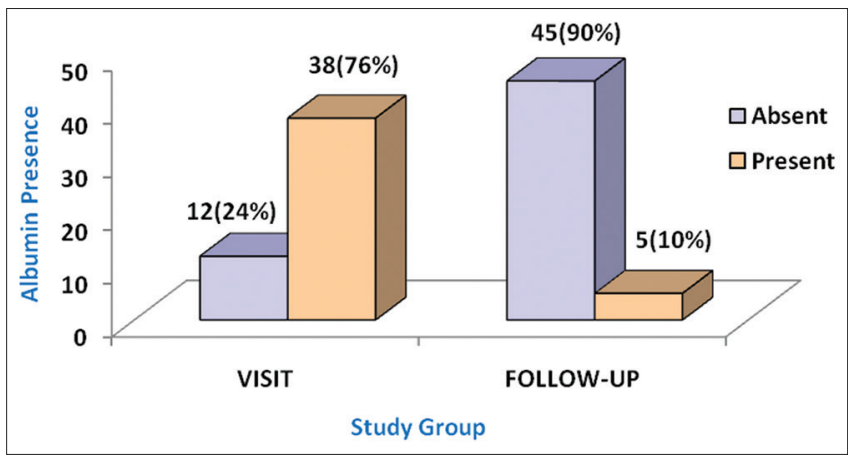

Fig. 6: Albuminuria at visit and follow-up

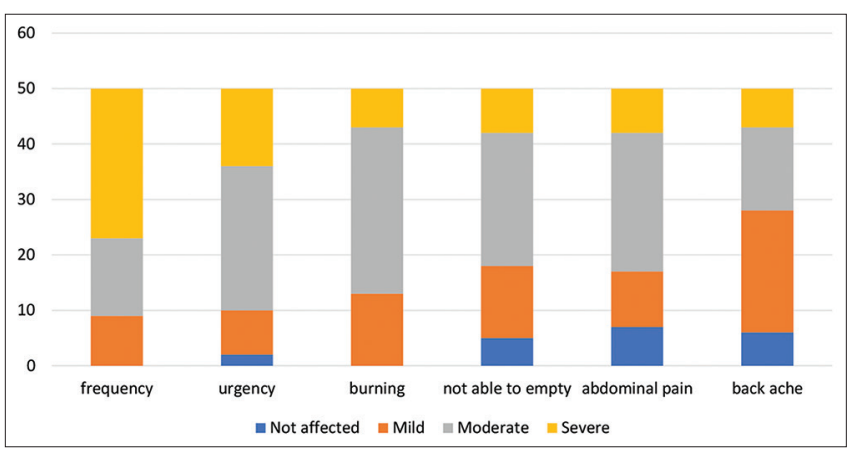

Fig. 7: Effect of symptoms on quality of life during visit

All the domains showed progress in the clinical features after the treatment which is comparable to other studies [6]. The severity of symptoms reduced from $84 \%$ to $8 \%$ during the follow-up period. Impact 


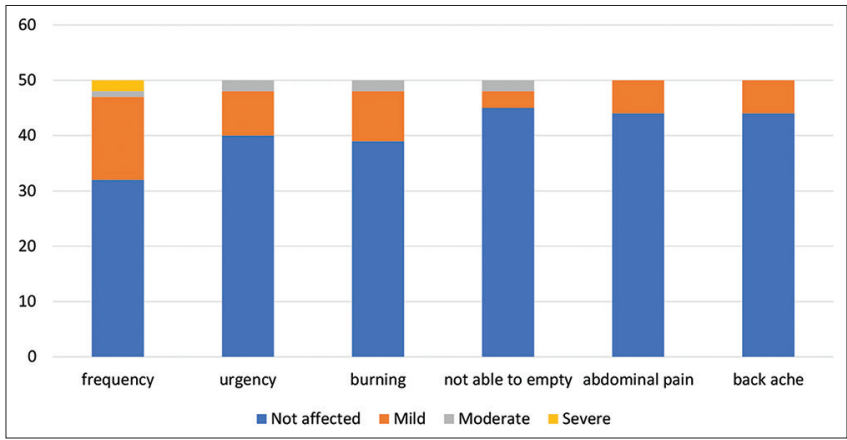

Fig. 8: Effect of symptoms on quality of life during follow-up

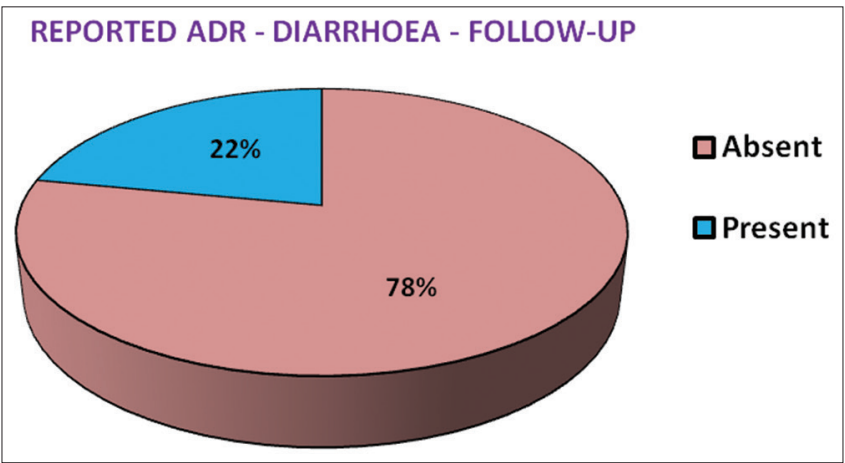

Fig. 9: Side effects of the drug

of symptoms on quality of life drastically improved post-treatment. The cure rate of $98 \%$ in the present study is comparable to other studies [6].

Among the 50 patients incorporated in ongoing study, 11 patients $(22 \%)$ reported diarrhea after medication consumption. The incidence of diarrhea is much higher compared to other studies which is around $2 \%[3,7]$. Other side effects such as vaginitis and nausea seen in other studies were not reported in our study [8].

\section{CONCLUSION}

The current study proves that single dose of FT can be used for the treatment of uncomplicated UTI. The single dose intake makes it more compliant compared to rest of the drugs used for the treatment of UTI. The quality of life of the patients' improved significantly after the treatment which was analyzed by UTISA pre- and post-treatment questionnaire making it a valuable tool in the study.

\section{Limitations}

The small sample size of the study can restrict the ability to recognize difference between groups. Urine culture was not done for confirmation of UTI and drug sensitivities were unavailable. This is a single arm study and treatment regimens were not compared with other UTI treatments.

\section{AUTHORS CONTRIBUTION}

Manoj Kumar and Manisha had prepared questionnaire and data collection. Sai Sree and Kamala reviewed the data literature and statistical analysis. Sashidhar Reddy prepared the draft, manuscript writing, analysis review, and the final editing.

\section{CONFLICTS OF INTEREST}

None.

\section{FUNDING}

None.

\section{REFERENCES}

1. Manish M, Vaibhav R, Shankar S. Fosfomycin single-dose oral antibiotic for uncomplicated UTI a review. Indian Pract 2019;72:34-41.

2. Medina M, Pino EC. An introduction to the epidemiology and burden of UTI. Ther Adv Urol 2019;11;3-7.

3. Huttner A, Kowalczyk A, Turjeman A, Babich T, Brossier C, EliakimRaz N, et al. Effect of 5 day nitrofurantoin vs single dose Fosfomycin on clinical resolution of uncomplicated lower UTI in women; a randomized clinical trial. JAMA 2018;319:1781-9.

4. Cai T. Recurrent uncomplicated UTI; definition and risk factors. GMS Infect Dis 2021;9:Doc03.

5. Bradley JG, Andrew JS, Iain JA, Anton YP. Nitrofurantoin and fosfomycin for resistant urinary tract infections: Old drugs for emerging problems. Aust Prescr 2019;42:14-9.

6. Bedi P, Singh K, Wariach P. Study of fosfomycin trometamol in acute lower urinary tract infection. J. Evol Med Dent Sci 2016;5:1649-50.

7. Clayson D, Wild D, Doll H, Karen K, Gondek K. Validation of a patient administered questionnaire to measure the severity and bothersomeness of lower urinary tract symptoms in an uncomplicated UTI: The UTI symptom assessment questionnaire. BJU Int 2005;96:350-9.

8. Dmitri I, Ronald W, John F, Sumathi N. Adverse events associated with fosfomycin use: Review of literature and analyses of FDA adverse event reporting system database. Infect Dis Ther 2015;4:433-58.

9. Stein GE. Comparison of single dose of Fosfomycin and a 7 day course of nitrofurantoin in female patients with uncomplicated UTI. Clin Ther 1999;21:1864-72.

10. Speight TM, Holford NH. Avery's Drug Treatment: Guide to Properties, Choice, Therapeutic Use, Economic Value of Drugs in Disease Management. Vol. 2. India: Wiley; 2012. p. 1072-3.

11. Jameson JL, Fauci AS, Kasper DL, Hauser SL, Longo DL, Loscalzo J. Harrison's Principles of Internal Medicine, Part-8: Infectious Diseases. New York: McGraw Hill; $19^{\text {th }}$ ed. 2016. p. 861-4.

12. Antimicrobial Use in Common Syndromes Treatment Guidelines by ICMR New Delhi, Chapter-9, Management of UTI's; 2019. p. $86-92$.

13. Ralston S, Penman I, Strachan M, Hobson R. Davidson's Principles and Practice of Medicine. $23^{\text {rd }}$ ed., Ch. 17. London, United Kingdom: Churchill Livingstone; 2017. p. 511-3.

14. Raz R. Fosfomycin: An old new antibiotic. Clin Microbiol Infect 2012;18:4-7.

15. Aghamali M, Sedighi M, Bialvaei AZ, Mohammadzadeh N, Abbasian S, Ghafouri Z, et al. Fosfomycin mechanisms and the increasing prevalence of resistance. J Med Microbiol 2018;68:11-25.

16. Ahmed B, Clarker L, Doi Y, Shields RK. Fosfomycin for treatment of multidrug-resistant pathogens causing urinary tract infection: A realworld perspective and review of literature. Diagn Microbiol Infect Dis 2019;95:114856

17. Ten Doesschate T, van Werkhoven H, Meijvis S, Stalenhoef J, van Zuilen A, de Vries A, et al. Fosfomycin trometamol for UTIs in kidney transplant recipients. Transplantation 2019;103:1272-6.

18. Mai C, Donaghy H, Doan T. Oral fosfomycin use for urinary tract infections and its clinical impact on hospital stay. Open Forum Infect Dis 2018;5 Suppl 1:S473.

19. Dijkmans AC, Zacarias NV, Burggraaf J, Mouton JW, Wilms EB, van Nieuwkoop C, et al. Fosfomycin: Pharmacological, clinical and future perspectives. Antibiotics (Basel) 2017;6:24

20. Matthews PC, Barrett LK, Warren S, Stoesser N, Snelling M, Scarborough M, et al. Oral fosfomycin for treatment of urinary tract infection a retrospective cohort study. BMC Infect Dis 2016;16:556

21. Qiao LD, Zheng B, Chen S, Yang Y, Zhang K, Guo HF, et al. Evaluation of three dose fosfomycin tromethamine in treatment of patients with urinary tract infections: An uncontrolled, open label, multicenter study. BMJ Open 2013;3:e004157.

22. Neuner EA, Sekeres J, Hall GS, van Duin D. Experience with fosfomycin for treatment of urinary tract infections due to multi drug-resistant organisms. Antimicrob Agents Chemother 2012;56:5744-8.

23. de Jong Z, Pontonnier F, Plante P. Single dose fosfomycin trometamol(Monuril) versus multiple dose norfloxacin results of multicenter study in females with uncomplicated lower urinary tract infections. Urol Int 1991;46:344-8.

24. Stein GE. Single dose treatment of acute cystitis with fosfomycin tromethamine. Ann Pharmacother 1998;32;215-9. 